\title{
Studies on Ligia oceanica. I. A. Habitat and Effect of Change of Environment on Respiration. B. Observations on Moulting and Breeding.
}

\author{
By
}

Aubrey G. Nicholls, B.Sc.

With 2 Figures in the Text.

\section{CONTENTS.}

INTRODUCTION

A. Habitat and Effect of Change of Environment on Respiration

1. Historical . . . . . . . . . . . . . . . 656

2. Habitat . . . . . . . . . . . . . . . . . . .

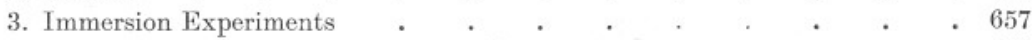

4. Effect of Change of Temperature on Respiration $\quad . \quad$. $\quad . \quad$. $\quad . \quad 659$

B. Observations on Moulting and Breeding

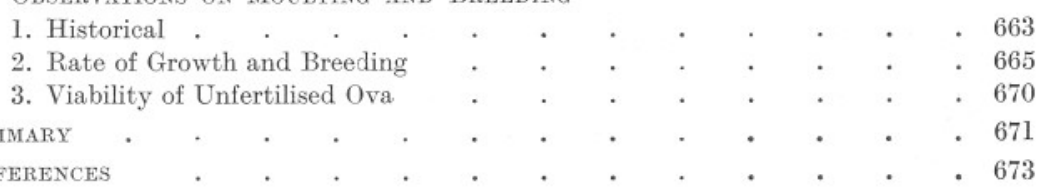

INTRODUCTION.

THIs paper is the outcome of work done at the Laboratory of the Marine Biological Association at Plymouth during the period October, 1929, to January, 1931, while holding a studentship under the Council for Scientific and Industrial Research of Australia.

It gives me pleasure at the outset to express my thanks to the Director and members of the staff at Plymouth for their interest and help in my work, also to the many visitors to the Laboratory who have given much assistance. In particular would I like to thank Dr. C. M. Yonge, without whose help part of this work would never have been attempted.

During the course of sixteen months at Plymouth several aspects of the biology of Ligia were touched on and it is my intention to deal with the subject under three headings. The first, "Habitat and Effect of Change of Environment on Respiration," will include a general description of the nature of the habitat of this animal with reference to its food, reaction to light, animals which prey upon it, and an account of some experiments upon its respiration. These latter were performed during the course of a short visit to the Marine Station at Millport, Scotland, and much of the 
success of the results is due to the interest displayed and assistance given by Miss S. M. Marshall and Mr. A. P. Orr. I have also to thank Mr. Elmhirst, the Superintendent, for permitting me to occupy a table at the Station during that period.

The second heading, "Observations on Moulting and Breeding," will cover work which occupied sixteen months during which the animals were watched in the Laboratory and notes taken on their moulting and breeding, with reference to temperature, etc. It will also include experiments to discover the viability of the unfertilised ova. In Part II will be described the structure of the foregut, and the paper will be concluded with a description of the processes of feeding, digestion, and absorption.

\section{A. HABITAT AND EFFECT OF CHANGE OF ENVIRONMENT ON RESPIRATION.}

\section{Historical.}

Though many workers, particularly in the last decade of the nineteenth century, have been interested in the lower Crustacea, attention was mainly devoted to the Amphipods or, where Isopods were investigated, the terrestrial members of that group received most attention. On the whole Ligia has come in for very little notice, though occupying a very interesting position amongst the Crustacea by virtue of its structure and habitat. Among the more recent workers, Tait (1917) has carried out experiments on immersion, moulting, limb-flexure, and colour change in Ligia; Stewart (1913) has also published the results of experiments on immersion in salt and fresh water. An excellent description of the general morphology of Ligia is provided by Hewitt (1907).

\section{Habitat.}

The distribution of Ligia is very wide, covering practically the whole of the north coast of Europe; it has also been recorded from Morocco and America. The natural habitat consists of crevices in rocks just above highwater mark, or where the beach is sandy they will be found under stones and rocks at a similar level. When occupying such an area very large specimens are rare, though females with brood pouches have been found frequently. The largest animals occur on rocky areas, and a particularly favourable spot is to be found along the quays at Plymouth where the mortar has been washed out from between the rocks composing the walls, forming ideal crevices in which to hide.

Ligia is a nocturnal animal, never appearing during the day unless disturbed, and for that reason always difficult to obtain in any quantity by daylight. At night, during low tide, they emerge in large numbers and descend to the lower levels of the walls on which is growing a thick layer 
of Fucus vesiculosus and other algæ. Here they feed, making the most of the time while the tide is out, and while the seaweed forms the main article of diet, nothing edible comes amiss, particularly if it be of the nature of animal offal. One specimen collected from the region above that affected by the sea-water and apparently feeding on moss was killed and the contents of the gut examined under a microscope. Amongst the material therein contained, moss capsules and part of a syncytium of Vaucheria were easily identified. Evidently this animal is not confined to marine vegetation.

When feeding in this manner, with the aid of a torch specimens can be collected in large numbers by simply walking along the base of the wall and picking the animals off the seaweed. They are quickly disturbed by the light and will retreat to the crevices if not captured quickly. The light of a bright moon is sufficient to prevent them from emerging. How they manage to feed on bright moonlight nights I am at a loss to explain, but experience proved time and again that it was useless to expect to obtain more than a dozen specimens from a wall which on dark nights provided 1000 specimens in just over two hours. Doubtless if they emerged during the day they would be preyed upon by sea-gulls and other birds, and as it is, when feeding at night, they are liable to fall a prey to the common shore crab, Carcinus monas. I have observed on several occasions an unfortunate Ligia caught, by a sudden movement of these usually slow moving animals, in the chelæ of a crab.

Only very young individuals are found in the open during the daytime and then not very abundantly. The young seem to have much less aversion to light than the mature animals, this being noticed in those bred in the laboratory as well as in nature.

\section{IMMERSION EXPERIMENTS.}

Though preferring a moist locality above high water, Ligia can withstand immersion for a considerable time in salt water. Stewart (1913) immersed a number of Ligia in fresh pond water and others in sea-water, but apparently took no measures to aerate the water with the natural result that all died within 48 hours, those in fresh water living longer than those in salt. These experiments were repeated, the water being changed continually with the result that they survived nine days, death being ascribed rather to lack of food than to the ill-effects of immersion. Tait (1917a) showed that specimens immersed in sea-water survived for more than 83 days ( 2 specimens) ; those immersed in half sea-water lived for, at the most, 42 days; those in quarter sea-water only 15 days, while others immersed in distilled water lived only a matter of hours. Care was taken in every case to aerate the water. He showed, moreover, that during that period of immersion those living in clean sea-water fasted, and moulted normally. 
During the course of my investigations I carried out similar experiments with animals of varying ages, employing the method in use by Sexton and Clark of gradually changing the salinity of the water by adding a constant amount of fresh water daily, having first removed a similar quantity. The volume was kept constant by the addition of distilled water to counteract evaporation. The water was aerated by passing a fine stream of air through it and a small piece of Fucus was placed in each jar for food and as an object of attachment for the Ligia. This, though not important, is useful, as otherwise the animals will wander round and round the bottom of the jar, periodically swimming vigorously about in an apparent attempt to escape. If only a stone or shell be placed at the bottom Ligia will soon settle down upon it.

Two jars, K1, E1, were employed containing each about 300 c.c. seawater, and four, K2, E2, E3, E4, containing each 250 c.c. Into each jar were placed three small Ligia on 2nd December, 1929. In the two jars, $\mathrm{K} 1$, K2, used as controls, the level of the water was maintained by the addition of distilled water as required, and of the remaining four 5 c.c. of water from E1, 10 c.c. from E2 and E3, and 25 c.c. from E4 were removed daily, a similar quantity of fresh (tap) water being substituted. Moulting was observed to occur in these young specimens.

Those undergoing the quickest dilution died first, surviving only five days, while those in E2 and E3 were dead by 14th December, having survived less than 12 days. There were animals still alive in K2 and E1 at the end of the month.

An interesting record was that of an adult animal which at some time had fallen into a large jar of sea-water and become quite at home. This jar was taken as a whole and placed under the system of aeration and dilution (E5), 25 c.c. being removed daily from a total volume of about 2 litres. This started on 10th December.

It was noticed that the rate of beating of the pleopods appeared to be considerably faster than when placed in sea-water, accordingly the time for 100 beats was measured with a stop-watch, as follows :-

On 24 th December time for 100 beats $60 \cdot 8$ secs.

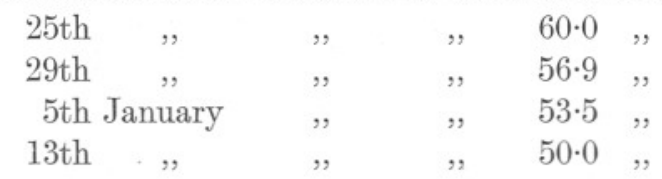

showing a steady increase in rate of beating with further dilution of the sea-water. This was compared with the rate of beating of another specimen which had been in sea-water for some time and it was found that this animal beat its pleopods very rarely and then only for a short time and very slowly unless disturbed, when it would beat at the rate of 50 beats 
in $65 \cdot 7$ secs. On January 13 th this specimen, E5 - a female-was due to moult but succumbed in the attempt, probably due to asphyxiation during the process of liberating its pleopods.

While at Millport specimens had been collected from beneath stones and small rocks that were moistened by a stream of fresh water running into the sea, and when the tide rose were actually covered by water which would have a very reduced salinity. Water from this pool was kindly tested by Mr. Elmhirst and was shown to have a salinity only slightly above that of normal fresh water.

\section{Effect of Change of Temperature on Respiration.}

The following series of experiments carried out at Millport gives some idea of the effect of change of temperature on the animal as a whole, though most strikingly demonstrated by the change in rate of beat of the pleopods. The first shows the effect of sudden change in temperature.

Three specimens were placed in sea-water at ordinary room temperature, and thermos flasks were prepared containing water at definite temperatures. Into the neck of each flask was fitted a test-tube containing sea-water at the same temperature as that in the flask; the tubes were corked to prevent loss of heat, and provided with thermometers. The animals for experiment were then transferred to these tubes with the following results :-

\section{TABLE I.}

Effect of Sudden Change in Temperature on Ligia Immersed in Sea-Water.

At 4.35 p.m. Specimen A was placed in sea-water at $25^{\circ} \mathrm{C}$. 5.03 p.m. apparently unharmed.

6.00 p.m. changed to flask at $35^{\circ} \mathrm{C}$.

7.35 p.m. temperature down to $30^{\circ}$ C., animal almost dead, transferred to water at $15^{\circ} \mathrm{C}$.

8.35 p.m. quite recovered.

At 4.35 p.m. Specimen B was transferred to sea-water at $30^{\circ} \mathrm{C}$. 5.03 p.m. $\quad$ still living, temperature $29^{\circ} \mathrm{C}$.

5.53 p.m. $\quad$ apparently dead, temperature $29^{\circ}$ C., transferred to water at $15^{\circ} \mathrm{C}$.

7.35 p.m. had not recovered.

At 4.35 p.m. Specimen $\mathrm{C}$ was transferred to sea-water at $35^{\circ} \mathrm{C}$. 4.43 p.m. unable to flap pleopods, tending to curl up, to all appearances dead, replaced in cold sea-water.

5.23 p.m. completely recovered. 
Thus it will be seen that the greater the rise in temperature the shorter the period of survival and yet though apparently dead, that is when all movement of the pleopods has ceased, if transferred to more normal conditions the animal may recover. Specimen $\mathrm{C}$ withstood a temperature of $35^{\circ} \mathrm{C}$. for 8 minutes and then recovered, though apparently dead. Specimen B having been subjected to $30^{\circ} \mathrm{C}$. for half an hour was unaffected, though a further 50 minutes was sufficient to kill it.

This experiment led naturally to an attempt to discover the lethal temperature for this animal when subjected to a gradual increase in temperature, and a comparison of its survival in air under those conditions with its survival in water.

A large tank was set up filled with water which was stirred mechanically and the temperature controlled by a thermostat. Into this tank was placed a number of small bottles each containing one Ligia, 30 specimens being used in all. Half of these bottles were filled with sea-water and the other half contained only the animals, five adult males, five adult females, and five young specimens being used in each experiment. In order that those immersed in water should not suffer from lack of oxygen the water was changed at regular intervals, care being taken to ensure that the added water was at the appropriate temperature. Each bottle was numbered and those filled with air were fixed into a wire basket and weighted to keep them properly submerged.

The water in the thermostat was raised $1 \cdot 0^{\circ} \mathrm{C}$. every hour and kept constant for that period. The sea-water inside the bottles was changed once every three hours. The time of death of each animal was noted along with the temperature. This information will be found summarised in Table II.

TABLE II.

Showing Temperature at which Death Occurred for Individuals IN AIR AND IN Water.

\begin{tabular}{|c|c|c|c|c|c|c|c|}
\hline Temp. & 28 & 30 & & 31 & 32 & 33 & 34 \\
\hline \multicolumn{8}{|c|}{ IN AIR. } \\
\hline Males & - & - & & - & - & - & 2 \\
\hline Females & - & - & & - & - & 1 & 2 \\
\hline Young & - & - & & - & - & - & 5 \\
\hline & & & IN & WATER. & & & \\
\hline Males & 1 & 2 & & - & 2 & - & - \\
\hline Females & - & - & & - & 1 & 2 & 1 \\
\hline Young & - & 1 & & - & 1 & 1 & 2 \\
\hline
\end{tabular}


TABLE III.

Showing Number of Beats per minute with increased Temperature in Males, Females, and Young.

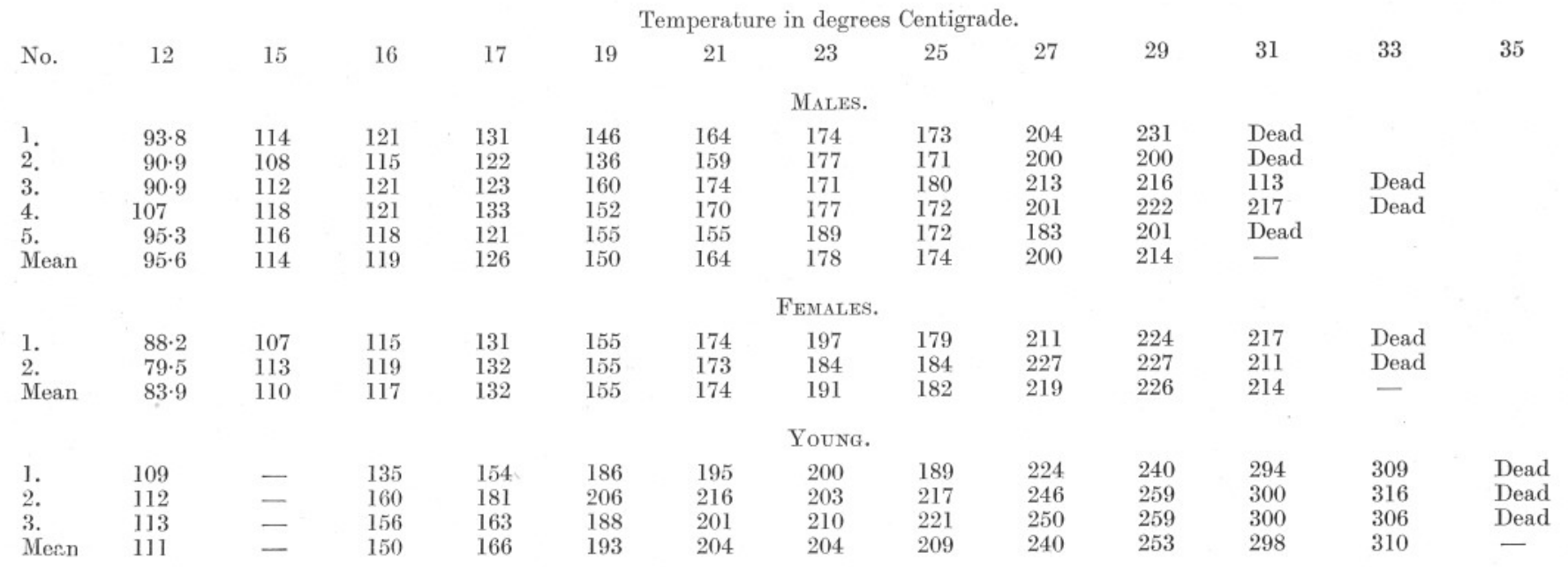


The lethal temperature in air lies at about $34^{\circ} \mathrm{C}$., though a certain proportion survived that temperature for one hour and withstood for a short time a further rise to $35^{\circ} \mathrm{C}$., though none for more than 10 minutes. When immersed in water the adult males seem to be much less able to withstand any increase in temperature above $30^{\circ} \mathrm{C}$., while the majority of adult females and young of both sexes succumbed between $32^{\circ}$ and $34^{\circ} \mathrm{C}$.

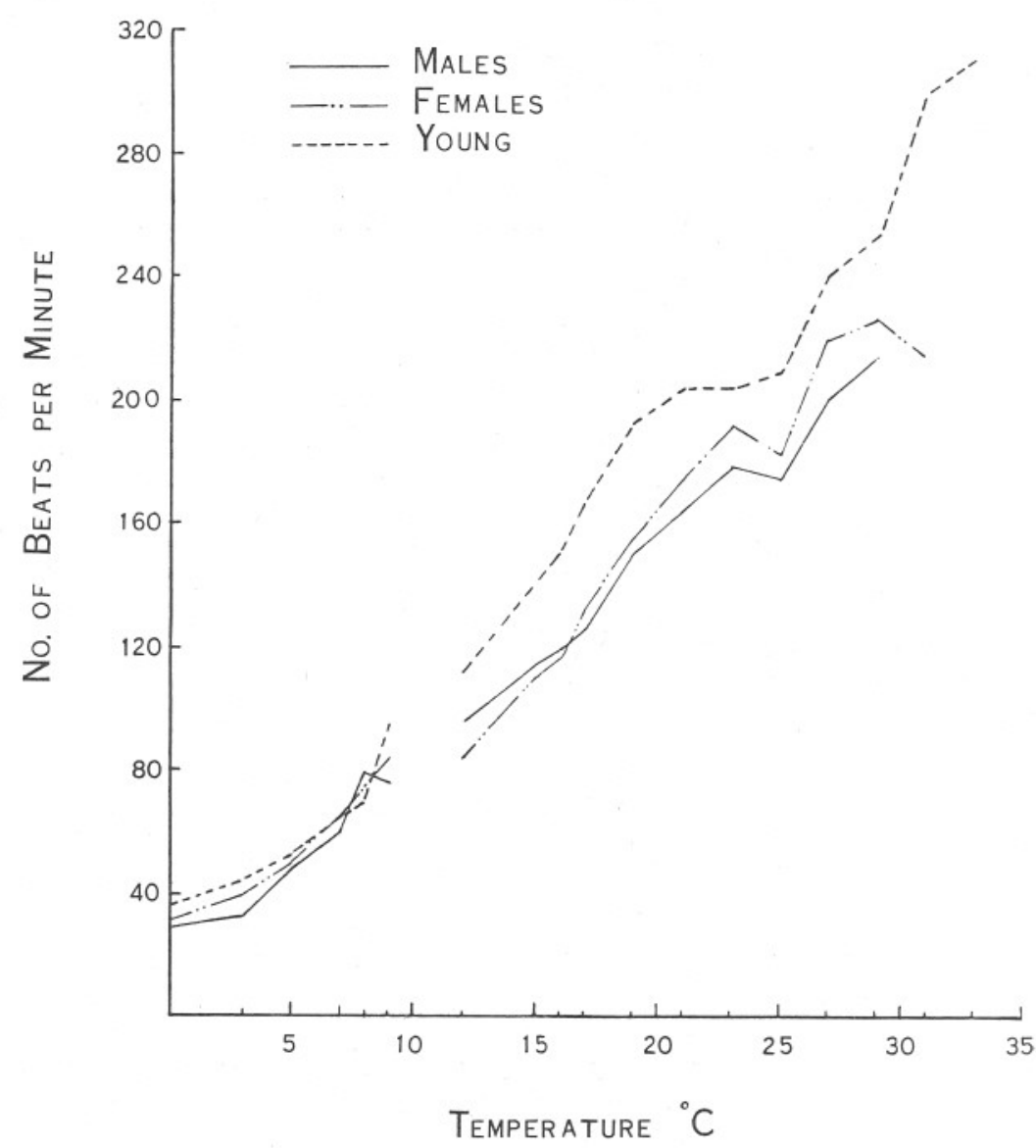

FIG. 1.-Graph showing the change in rate of beating of the pleopods with change in temperature; drawn from the averages of the males, females, and young in Tables III and IV.

Respiration seems to be the limiting factor for immersed animals; the continued beating of the pleopods to obtain sufficient oxygenation of the blood while immersed, and the consequent drain on the energy of the animal would account for the earlier death of immersed animals compared with those in air. It was apparent that as the temperature was increased 
the rate of beat of the pleopods also increased. With a view to obtaining data on the increase in rate of beat the above experiment was repeated on a number of animals immersed in water, the time taken for 100 beats being measured with a stop-watch at the end of each hour. In addition to starting at room temperature and gradually increasing it another experiment was run simultaneously in which, by adding ice, the temperature was lowered finally to zero. The results of these experiments, expressed as the number of beats per minute, will be found in Tables III and IV and depicted graphically in Figure 1.

\section{TABLE IV.}

Showing Number of Beats per Minute with Decreased Temperature in Males, Females, and Young.

\begin{tabular}{|c|c|c|c|c|c|c|c|c|}
\hline \multirow{2}{*}{ No. } & & & \multicolumn{6}{|c|}{ Temperature in degrees Centigrade. } \\
\hline & & & 9 & 8 & 7 & 5 & 3 & 0 \\
\hline \multicolumn{9}{|c|}{ Males. } \\
\hline 1 & . & . & $75 \cdot 8$ & $75 \cdot 8$ & $64 \cdot 4$ & $56 \cdot 0$ & $35 \cdot 3$ & $29 \cdot 9$ \\
\hline $2 \quad$. & . & . & $76 \cdot 5$ & $82 \cdot 0$ & $56 \cdot 2$ & $39 \cdot 9$ & $30 \cdot 7$ & $28 \cdot 7$ \\
\hline Mean & . & . & $76 \cdot 2$ & $78 \cdot 9$ & $60 \cdot 3$ & $48 \cdot 0$ & $33 \cdot 0$ & $29 \cdot 3$ \\
\hline \multicolumn{9}{|c|}{ Females. } \\
\hline 1 & . & . & $92 \cdot 5$ & $82 \cdot 4$ & $72 \cdot 1$ & $59 \cdot 3$ & $42 \cdot 0$ & $34 \cdot 3$ \\
\hline 2 & . & . & $75 \cdot 8$ & $67 \cdot 6$ & $59 \cdot 1$ & $40 \cdot 2$ & 37.7 & $28 \cdot 7$ \\
\hline Mean & . & . & $84 \cdot 2$ & $75 \cdot 0$ & $65 \cdot 6$ & $49 \cdot 8$ & $39 \cdot 9$ & $31 \cdot 5$ \\
\hline \multicolumn{9}{|c|}{ YoUNG. } \\
\hline 1 & . & . & $96 \cdot 8$ & $74 \cdot 3$ & $69 \cdot 9$ & $56 \cdot 8$ & $48 \cdot 9$ & $36 \cdot 1$ \\
\hline 2 & . & . & $92 \cdot 6$ & $65 \cdot 2$ & $60 \cdot 0$ & $49 \cdot 5$ & $41 \cdot 6$ & 36.9 \\
\hline Mean & . & . & $94 \cdot 7$ & $69 \cdot 8$ & $65 \cdot 0$ & $53 \cdot 2$ & $45 \cdot 3$ & $36 \cdot 5$ \\
\hline
\end{tabular}

On reference to Figure 1 it will be seen that in effect it is a straight line graph, indicating as constant change in rate of beat as the temperature rises or falls between $5^{\circ}$ and $35^{\circ} \mathrm{C}$. Between $5^{\circ}$ and $0^{\circ} \mathrm{C}$., however, there is a tendency for the rate to become constant.

\section{B. OBSERVATIONS ON MOULTING AND BREEDING.}

\section{Historical.}

In October, 1929, a number of Ligia were brought into the laboratory and kept under observation to watch the process of moulting and in the hope of inducing them to breed. Since they were found under natural conditions feeding on Fucus it was thought that they might survive for some time if placed on moist Fucus in a bowl and covered to prevent evaporation. To this end a number of finger bowls were employed, in each were placed a piece of Fucus vesiculosus and a pair of animals to be 
observed and they were then covered with glass squares. Each bowl bore a numbered label.

It was found by experience sufficient to wash the bowls and weed in seawater two or three times a week and to change the weed about once a fortnight during the winter. In summer more frequent changing of the weed was required, with washing on alternate days. Under these conditions the animals lived, fed, moulted, grew, and bred apparently quite normally for several months, some surviving 15 months before being killed, while one is still alive at the time of going to press.

The cast cuticles of each animal, when not eaten, were preserved $(70 \%$ alc.) and the animals measured as soon as the new cuticle had hardened after the process of moulting. Notes were taken of any changes in colour of the skin or eyes, condition of brood plates and other points of interest. From the information obtained it has been possible to reconstruct a fairly complete history of the life of the animal subsequent to emergence from the brood pouch.

As stated by Hewitt, the body is broadest across the fourth (free) thoracic segment, gradually decreasing in size posteriorly. This statement applies to all normal individuals with the exception of females which have developed mature brood plates, in which case the greatest breadth is in the third free thoracic segment, and by means of this distinction in shape animals with brood pouches can be picked out at a glance quite easily.

The colour of the eyes is normally black, but in a certain proportion, particularly females, a chocolate brown occurs which is most noticeable after each moult, gradually darkening as the new "skin " grows older. In one young specimen found towards the end of 1929 the colour of the eyes was noticed to be very bright red, while the general body colour was very pale, almost white, probably due to lack of development of chromatophores.

The process of moulting has been described by Tait (1917b) and it will suffice here merely to add the results of a few of my observations. With reference to the "chalky whiteness" which appears some time before moulting on the ventral side of the first four free thoracic segments, rough tests of its composition made by me support the statement of Herold (1913) that it is a deposition of calcium carbonate. A gas that will not support combustion is evolved when treated with acid, and the flame test indicates calcium. This deposit appears a number of days before moulting, the period varying with the time of year and the age of the animal, as does also the interval between the posterior moult and the anterior. The longest times are shown in adult males during winter (average laboratory temperature about $14^{\circ} \mathrm{C}$.), when the first appearance of the deposit may precede the moult of the posterior portion by six days and there are four full days between the moulting of the posterior and anterior portions; while the shortest times occur in young specimens in summer, when the 
first appearance of the deposit, the posterior moult and the anterior moult follow one another on successive days. The average laboratory temperature in summer was about $18^{\circ} \mathrm{C}$. Further it may be worth noting that, though there was little or no tendency for Ligia to eat their cast "skins" during the earlier part of their captivity, towards the end of the period this tendency became more and more marked until it was seldom that one could rescue a complete moult for preservation.

\section{Rate of Growth and Breeding.}

In Table $\mathrm{V}$ will be found figures showing the total increase in size for a number of animals over different periods. It was noticed that members of both sexes grew until a certain size was attained, after which further moulting showed no increase.

\section{TABLE V.}

\section{Showing Total Growth over a Given Period for a NUMBER OF ANIMALS.}

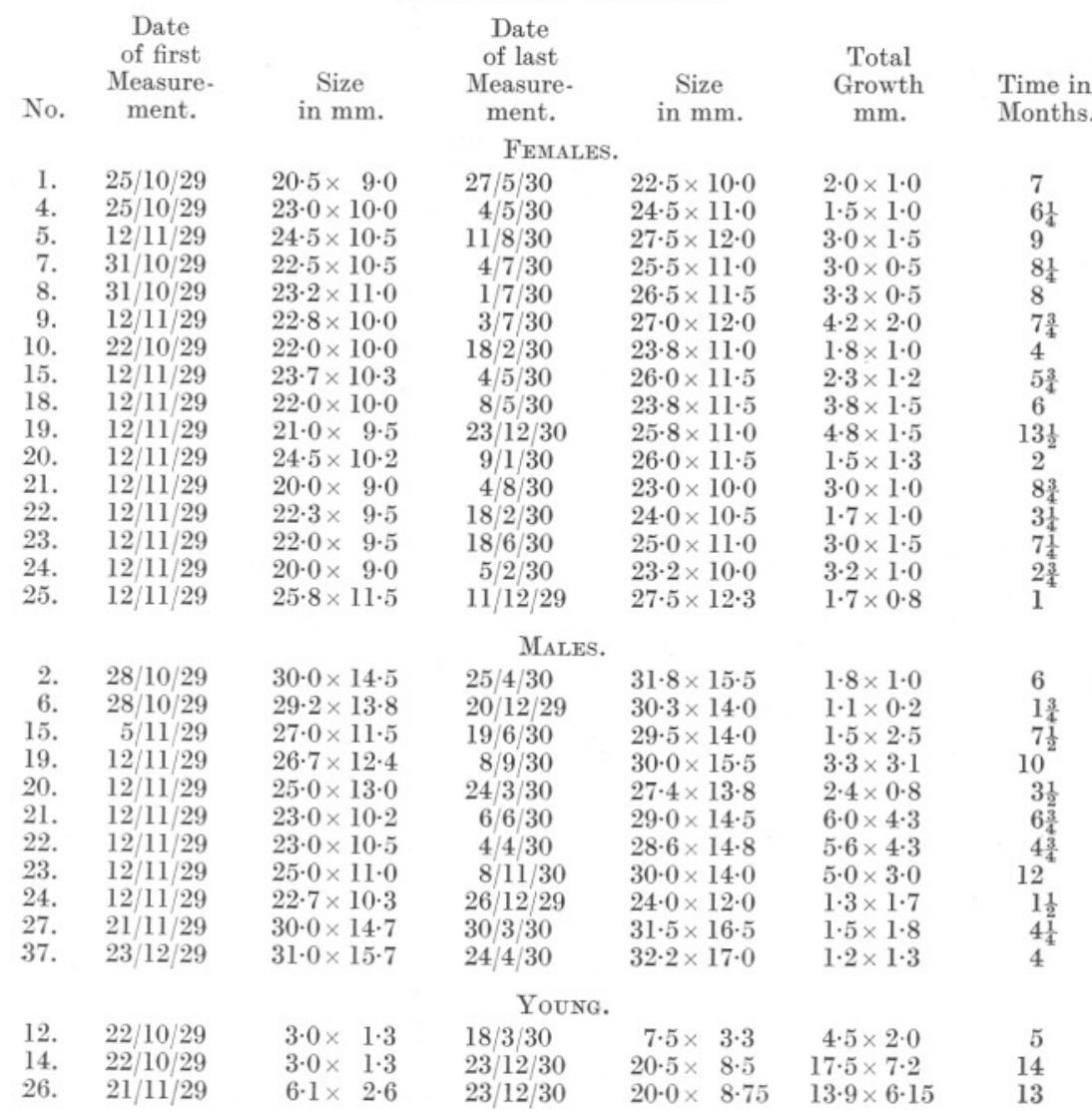

NEW SERIEs.-Vol. xvir. No. 3. остоBer, 1931. 
Two young $(3 \cdot 0 \times 1 \cdot 3)$ liberated from the brood pouch on 22 nd October, 1929, were kept alive in the laboratory. These both moulted within a fortnight and again at the end of a second fortnight, this being continued with gradually increasing intervals until April, 1930, by which time the interval between moults was just over a month. Growth was not the same in both cases, No. 12 moulting a few days before No. 14 and showing a greater increase with each moult. By the end of January, 1930, moreover, after the sixth moult the larger specimen was discovered to be a male, the appendages appearing in the "skin " of the 7th moult. No. 14 at this time showed no signs of secondary sexual characters and was assumed, therefore, to be a female, the brood plates being expected to appear at a later stage. At this time, March 16th-18th, their respective sizes were, male : $9 \cdot 2 \times 4 \cdot 0 \mathrm{~mm}$. and female : $7 \cdot 5 \times 3.3 \mathrm{~mm}$, and from now until the beginning of September the interval between the moults decreased, averaging about $2 \frac{1}{2}$ weeks.

The size attained by April was such that it was found impracticable to measure the animals accurately. They were still too small to be held in the fingers as larger animals were treated and were too strong to be held on the measuring slide with $a_{0}$ brush, the method employed on them up to date. Thus no measurements were taken through April, May, June, and July. During the latter month No. 14 escaped, a most unfortunate loss. It was not until the moult of July 2 nd that the brood plates appeared in this animal and it was noticeable that after this moult it was larger than the male, having also decreased the interval between moults relative to the male, so that now No. 14 was moulting a week before No. 12, a complete reversal of the previous state of affairs. It was at this most interesting point that the specimen was lost.

The male, No. 12, continued to grow, and by the end of July had attained to $15.0 \times 6.5 \mathrm{~mm}$. Five successive moults brought it to $20.5 \times$ $8.5 \mathrm{~mm}$. at the end of December and after moulting again in January, 1931, was fixed at the beginning of February, having survived $14 \frac{1}{2}$ months. There is apparently only a very slight variation in the rate of growth in summer and winter, the specimen holding very closely to an increase of $1.3 \times 0.5 \mathrm{~mm}$. at each moult, which was the average for the whole period. The summarised histories of these two will be found in Table VI.

To return to the female. Had not the specimen been lost it is safe to assume that it would have been at least as large as the male in December (in view of its sudden increase in size relative to the male in July), by which time it would have reached maturity and would have been able to produce a brood; in support of this we have the evidence of three females (No. 43) who all produced broods on attaining a size of $22.0 \times 9.5$ or $10.0 \mathrm{~mm}$. and also the record of one female measuring only $19.0 \times 8.5 \mathrm{~mm}$. which was found in the natural state with a brood. Thus we see that within 16 
months of birth, probably earlier, a female may produce her first brood of young. Further, we see that by June, when the second brood might be expected, the animal has attained a size of $24.5 \times 10.0 \mathrm{~mm}$. (No. 21) and from the history of No. 16 we see that this animal after having a period of rest through the autumn might start breeding again in January with a fourth brood in May and a fifth in August, most probably dying after liberating that brood in November.

TABLE VI.

Number 12.

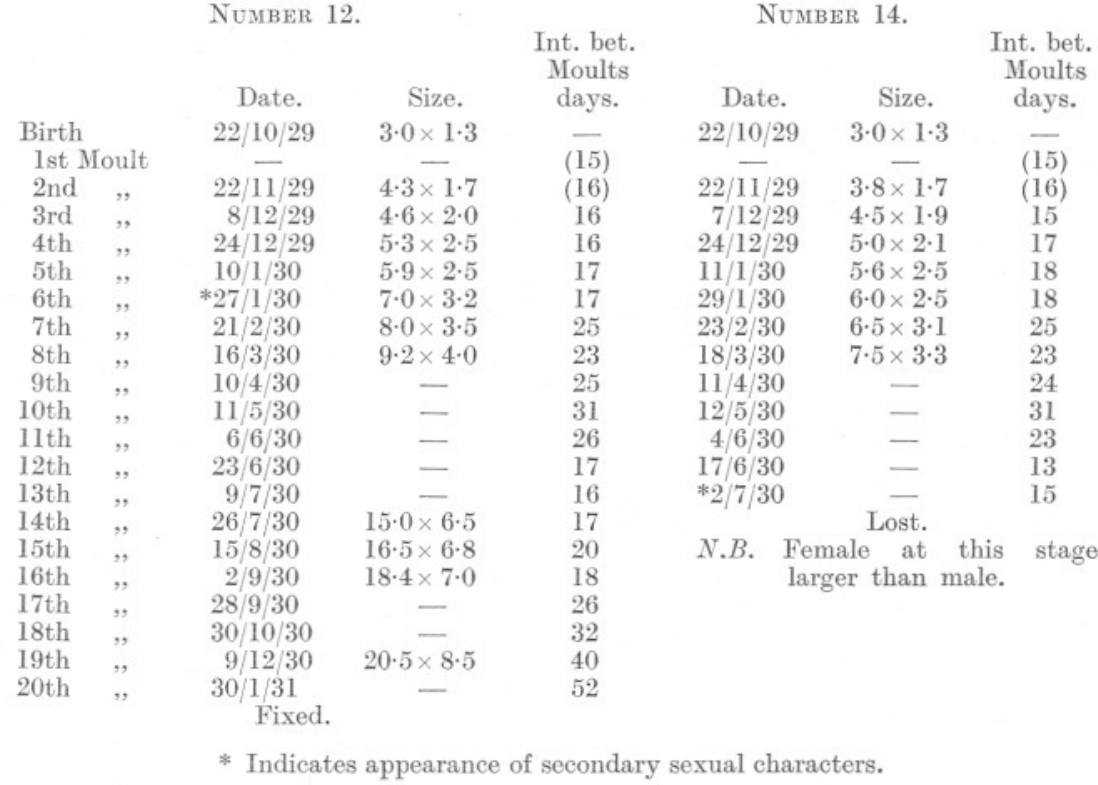

This hypothetical case has been constructed from data obtained from the records of actual specimens, only the results from animals of comparable size being taken into consideration. The records of these animals referred to in the text will be found in Table VII.

TABLE VII.

Extracts from Histories of Nos. 21, 24, aNd 16.

$\begin{array}{lcccccc}\text { No. } & \text { Date of } & \text { Moult. } & \text { Size. } & \begin{array}{c}\text { Date of } \\ \text { Moult. }\end{array} & \text { Size. } & \text { Date of } \\ \text { Moult. } & \text { Size. } \\ \text { 21. } & 25 / 12 / 29 & 23 \cdot 0 \times 9 \cdot 1 & \dagger 7 / 2 / 30 & 23 \cdot 0 \times 10 \cdot 1 & 3 / 5 / 30 & 24 \cdot 0 \times 10 \cdot 2 \\ & \dagger 4 / 6 / 30 & 24 \cdot 5 \times 10 \cdot 0 & & & & \\ 24 . & 25 / 12 / 29 & 23 \cdot 5 \times 9 \cdot 6 & \dagger 5 / 2 / 30 & 23 \cdot 2 \times 10 \cdot 0 & & \\ 16 . & \dagger 22 / 5 / 30 & 25 \cdot 0 \times 11 \cdot 0 & 22 / 7 / 30 & 26 \cdot 0 \times 11 \cdot 0 & \dagger 19 / 8 / 30 & \end{array}$

$\dagger$ Indicates mature moult with brood. 
Thus it will be seen that the expected life of a female is just over three years, the first being one of active growth, maturity being reached early in the second with the production of perhaps two broods, while the third year might see the release of three broods, culminating in the natural death of the animal in winter. The average number of young produced in each brood is about 80 , a few cases of over 100 having been found, and sometimes as few as 40 , varying with the age of the animal.

In Table VIII will be found the dates of spawning of the animals kept in the laboratory. Through the winter the average period taken by the eggs to develop and be liberated from the date of spawning was about 90 days, the young embryos becoming pigmented at about 40 days ; as the summer approached this period was gradually reduced until a period of 40 days only was required for the whole process during mid-summer, No. 21 spawning on 5th June, pigmentation starting 27 days later, and the brood being liberated on 15th July.

\section{TABLE VIII.}

Showing Dates of Spawning and Months of Year in which Females were found with Brood Pouches.

No. Jan. Feb. Mar. Apr. May June July Aug. Sept. Oct. Nov. Dec.

1. $27 / 30-\frac{18}{18} / 30$ - $30 / 30--$ 
In Table VIII the figures refer to the day and year, being placed in the appropriate month column, the date being that of spawning. The dashes following each date indicate the months during which the brood was developed and liberated. The arrows (reversed) show that the specimen when collected possessed mature brood plates but that the brood had been liberated, e.g. No. 8 collected in October, found to have mature brood plates but young liberated, must have spawned in August and have had young in pouch through September into October.

From this table it will be seen that Ligia may be found with a brood during any month of the year, though the spring appears to be the main

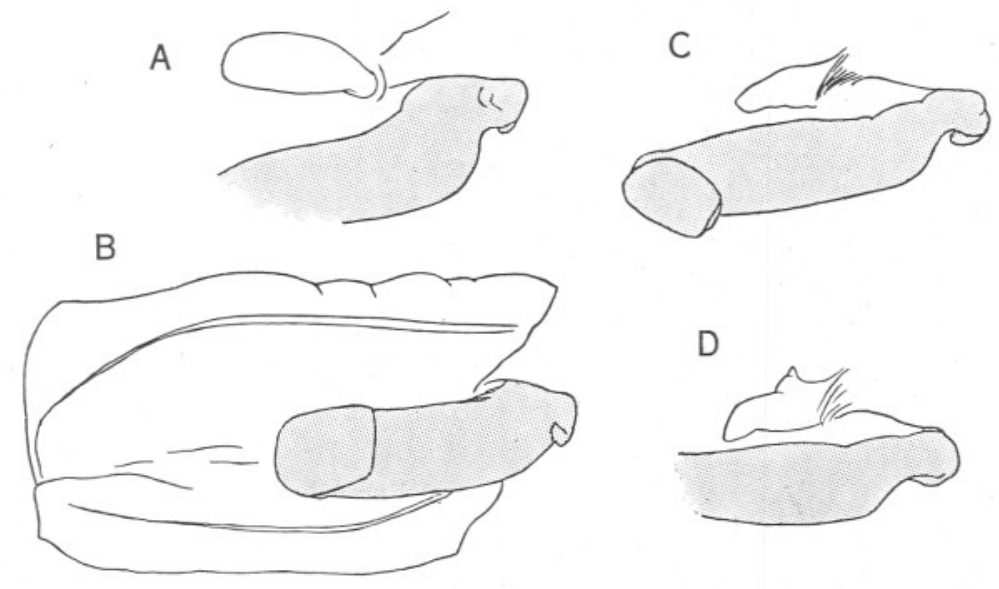

FIG. 2.-A, B, and C illustrate the form of the brood plates in three successive moults (drawn from No. 19). A. Normal condition. B. Mature condition. C. Reduced condition, always followed by a return to the normal. D. Reduced, with anterior projection; a modified form of $\mathrm{C}$ which occurs occasionally (drawn from No. 41). All drawn to the same scale.

breeding season, if that term can be applied to any part of the year in particular.

In the normal course of events about 10 days after the brood has been liberated the female moults, the mature brood plates (Fig. 2, в) being replaced with small ones, even smaller than those of the "normal" state (Fig. 2, A) in which they are rounded projections from the ventral sternites of the first five free thoracic segments of the body. Instead of being rounded, these "reduced" plates are pointed (Fig. 2, c). This condition is invariably followed by a return to the normal condition at the next moult. On a few occasions, without any relationship to temperature, season or any other factor apparently, a variant of the reduced condition appeared, the plates being pointed but each bearing a small projection on the anterior edge of the plate (Fig. 2, D). This state was followed by a return to the normal. 


\section{Viability of Unfertilised Ova.}

The following is an abstract from the history of the pair of animals, No. 23.

March 1st. Male carrying female; latter about to moult.

Male removed, female left to spawn alone.

2nd. Female moulted posterior.

4th. Female moulted anterior.

7th. Spawned.

(About May 14th. Young should have been liberated.)

24th. Female moulted posterior.

26th. Female moulted anterior.

29th. Male replaced.

Assuming that during the period in which the male was carrying the female spermatozoa were transferred to her, then it is obvious that these must have been cast off with the moult of 2 nd -4 th March, since the eggs did not develop, and thus, in order that the ova should be fertilised, copulation must occur subsequent to the moulting of the posterior portion at least. When the moult of the male coincides with that of the female, as happened in several instances, the male would be unable to effect the transference of sperm at the times of moulting each portion and thus it would be advantageous that the ova should remain fertilisable until the male had completed the moult. (In a state of nature it is not likely that the animals pair or that any one female is restricted to any one male and, therefore, the state of affairs described above would be purely due to laboratory conditions.) Nevertheless, it may be seen from the following extracts from the histories of two pairs of animals that the ova were fertilised despite the overlap of the moulting of male and spawning of female.

No. 32. Jan. 13th. Female moulted anterior.

14th. Male moulted posterior.

15th. Female spawned.

17th. Male moulted anterior.

Eggs fertile.

No. 36. Jan. 2nd. Female moulted anterior.

3rd. Male moulted posterior.

4th. Female spawned.

6th. Male moulted anterior.

Eggs fertile.

In both these cases the interval between the posterior and anterior moult of the male, during which the female spawned, was sufficient for 
the male to recover from the posterior moult and to fertilise the ova before proceeding to slough the anterior portion, but if for any reason copulation could not occur until the male had completed the moulting of the anterior, then a period of three days must elapse subsequent to the appearance of the eggs in the brood pouch before they could be fertilised. That they can survive this period is demonstrated by the following cases where the animals were separated for varying periods, the period of separation being the interval between the appearance of the eggs in the brood pouch and the reuniting of the male and female in the same bowl.

$\begin{array}{rrll}\text { No. 16. } 24 \text { hours separation. } & \text { Eggs infertile. } \\ 21 . & 40 \text { hours } \quad, & \text { Eggs fertile. } \\ \text { 19. } 3 \text { days } \quad, & \text { Eggs fertile. } \\ 6.14 \text { days } \quad, & \text { Eggs infertile. } \\ \text { 41. } 35 \text { days }, & \text { Eggs infertile. } \\ 23 . \quad 83 \text { days } \quad, & \text { Eggs infertile. }\end{array}$

No explanation for the infertility of No. 16 can be put forward other than the possibility of sterility in the male due to age; the male was full grown and died an apparently natural death in July, about six weeks after the date of spawning.

It is certain, however, that copulation must occur after the female has moulted the posterior portion and may be delayed until certainly three days after the eggs have appeared in the brood pouch. This indicates that the sperm are liberated into the cavity of the brood pouch rather than being passed into the oviducts. Copulation was observed in one case (No. 5) after the female had moulted the posterior portion and before moulting the anterior, in which case if the sperm were not passed into the oviducts they must have been retained beneath the brood plates of the fifth free thoracic segment. Possibly, of course, copulation was repeated after the completion of the anterior moult, certainly the eggs were fertilised.

\section{SUMMARY.}

1. Ligia is a nocturnal animal inhabiting crevices in rocks above hightide level. It is omnivorous though Fucus spp. form the main article of diet.

2. Immersion experiments were carried out in which the animals were subjected to a gradual transition from salt to fresh water. None survived this treatment for more than one month. It was noticed that the reduction in salinity was accompanied by an increase in the rate of beat of the pleopods.

3. Animals were subjected to sudden and gradual changes in temperature. One specimen survived a change from water at $15^{\circ} \mathrm{C}$. to water at 
$30^{\circ} \mathrm{C}$. for 28 minutes, but was dead after 78 minutes; a second, changed from water at $15^{\circ} \mathrm{C}$. to water at $35^{\circ} \mathrm{C}$., was to all appearances dead after 8 minutes, but recovered after being replaced in water at the original temperature.

4. The lethal temperature for Ligia, when subjected to gradual rise, was determined for males, females, and young in water and in air. Those in water died first, the males by the time $32^{\circ} \mathrm{C}$. was reached, the others succumbing between $32^{\circ}$ and $34^{\circ} \mathrm{C}$. The lethal temperature in air lies about $34^{\circ} \mathrm{C}$., a few surviving $35^{\circ}$ for a short time.

5 . The change in rate of beating of pleopods with change in temperature was determined for immersed males, females and young. The temperature of the water was raised from room temperature to the lethal temperature and lowered from room temperature to zero, the rate of beating being measured at regular intervals. The change in rate of beating is proportional to the change in temperature between $5^{\circ}$ and $35^{\circ} \mathrm{C}$. Below $5^{\circ} \mathrm{C}$. the rate of beating tends to become constant.

6. A number of Ligia were kept in the laboratory for a long time and moulting and breeding observed. The greatest interval between moults occurs in full grown males in winter, the shortest in young specimens during the summer.

7. The growth rate was observed in a young specimen to average $1.3 \mathrm{~mm}$. increase in length and $0.5 \mathrm{~mm}$. in width per month. The growth of a number of adults is tabulated.

8. A hypothetical reconstruction of the life of a female has been made from the histories of several specimens. It is estimated that the length of life of Ligia is 3 years, with a probable production of at least 5 broods of young. The average number of young per brood is 80 .

9. The time taken for the development of the young varies from 40 days in summer to 90 in winter.

10. The greatest number of animals with brood pouches is found in spring, but breeding occurs throughout the whole year.

11. In the moult following the liberation of the young the brood plates assume a shape (the reduced condition) distinct from that at any other time. This is followed by a return to the normal condition at the next moult. The reduced form is subject to variation in individuals.

12. Experiments indicate that copulation must occur subsequent to the appearance of the mature brood plates in the female. The ova are spawned about two days after the completion of the moult and, if unfertilised, remain viable for at least 3 days subsequent to their appearance in the brood pouch. 


\section{REFERENCES.}

Duvernoy, G. L., and Lereboullet, A. 1841. Sur la Respiration des Crustacés Isopodes. Ann. Sc. Nat., XV, pp. 177-240.

Emden, F. van. 1922. Zur Kenntnis der Brutpflege von Asellus aquaticus, nebst Bemerkungen über die Brutpflege anderen Isopoden. Arch. Natg., LXXXVIII, pp. 91-133.

Herold, W. 1913. Beiträge zur Anatomie und Physiologie einiger Landisopoden. Zool. Jahrb. Abt. f. Anat. u. Ontog., XXXV, pp. 457526.

Hewitr, C. G. 1907. Ligia. L.M.B.C. Memoirs, XIV, p. 37 (with 4 plates).

Mosley, C. 1915. Moulting of Oniscus asellus. Naturalist, London, pp. 284-285.

Sexton, E. W. 1924. The Moulting and Growth Stages of Gammarus with Description of the Normal and Intersexes of $G$. chevreuxi. Jour. Mar. Biol. Assoc., N.S., XIII, pp. 340-401.

Stewart, D. A. 1913. Changes in the Branchial Lamellae of Ligia oceanica after Prolonged Immersion in Fresh and Salt Water. Mem. \& Proc. Man. Lit. \& Phil. Soc., LVIII, Pt. 1, pp. 1-12 (with 2 plates).

TAIt, J. 1910. Colour Change in the Isopod Ligia oceanica. Jour. Phys. ; Proc. Phys. Soc., 40, pp. xl-xli.

TaIt, J. 1917a. Experiments and Observations on Crustacea. Part I. Immersion Experiments on Ligia. Proc. Roy. Soc. Edin., XXXVII, pp. 50-58.

Tait, J. 1917b. Experiments and Observations on Crustacea. Part II. Moulting of Isopods. Proc. Roy. Soc. Edin., XXXVII, pp. 59-68.

Unwin, E. E. 1908. Respiration in Oniscoidea. Rep. Brit. Ass., London, p. 736 .

Unwin, E. E. 1919. Notes upon the Reproduction of Asellus aquatious. Jour. Linn. Soc., XXXIV, pp. 335-342. 
